\title{
Research Paper: The Effect of Kinesio Taping on Pain, Functional Disability, and Trunk Range of Motion in People With Nonspecific Chronic Low Back Pain: A Single-group Pretest-Posttest Trial
}

\author{
Soheila Abbasi $^{1}$ (D), Mohammad Reza Hadian Rasanani ${ }^{1,2^{*}}$ (D), Nastaran Ghotbi ${ }^{1}$ (D), Gholam Reza Olyaei ${ }^{1}$ (D), Omid Rasouli ${ }^{3}$ (D) \\ 1. Department of Physiotherapy, School of Rehabilitation, Tehran University of Medical Sciences, Tehran, Iran. \\ 2. Department of Physiotherapy, Brain and Spinal Injury Research Center, Institute of Neuroscience, School of Rehabilitation, Tehran University of \\ Medical Sciences, Tehran, Iran. \\ 3. Department of Public Health and Nursing, Department of Mental Health, Faculty of Medicine and Health Sciences, Norwegian University of Science \\ and Technology, Trondheim, Norway.
}

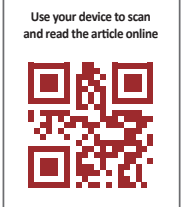

citation: Abbasi S, Hadian Rasanani M, Ghotbi N, Olyaei G, Rasouli O. The Effect of Kinesio Taping on Pain, Functional Disability, and Trunk Range of Motion in People With Nonspecific Chronic Low Back Pain: A Single-group Pretest-Posttest Trial. Journal of Modern Rehabilitation. 2020; 14(1):47-54. http://dx.doi.org/10.32598/JMR.14.1.6

dol'http://dx.doi.org/10.32598/JMR.14.1.6

Article info:

Received: 04 Jul 2019

Accepted: 23 Oct 2019

Available Online: 01 Jan 2020

\section{Keywords:}

Low back pain, Kinesio taping, Functional disability, Range of motion

\begin{abstract}
Introduction: This study aimed to evaluate the effect of Kinesio Taping (KT) on low back/ pelvis pain, disability, and trunk Range of Motion (ROM) in individuals with nonspecific chronic low back pain (CLBP) after $72 \mathrm{~h}$.

Materials and Methods: Eighteen patients with nonspecific CLBP participated in this study. Pain intensity, Oswestry low back pain disability questionnaire, and lumbar ROM were evaluated once before the intervention (KT with $50 \%$ tension) and then $72 \mathrm{~h}$ after. For statistical analysis, we used the paired sample t-test.

Results: Pain intensity was significantly reduced $(\mathrm{P}<0.01)$. But KT did not improve disability and lumbar ROM $(\mathrm{P}>0.05)$.

Conclusion: Based on the results, $72 \mathrm{~h} \mathrm{KT}$ over the lumbopelvic area did not improve disability and lumbar ROM in people with nonspecific CLBP while there was a significant reduction in pain intensity. The proposed mechanism of the KT effects is inconsistent with these results.
\end{abstract}

\section{Introduction}

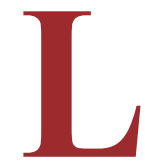

ow Back Pain (LBP) is one of the most common musculoskeletal impairments causing problems such as a functional disability in everyday activities and an increase in healthcare costs $[1,2]$. Nonspecific LBP is a type of LBP that its prevalence is about $85 \%$ to $95 \%$ of all people have LBP [1]. In a study conducted in Iran, $62 \%$ of the nursing population and $84 \%$ of pregnant women have experienced LBP in their lifetime [3, 4].

* Corresponding Author:

Mohammad Reza Hadian Rasanani, PhD.

Address: Department of Physiotherapy, School of Rehabilitation, Tehran University of Medical Sciences, Tehran, Iran.

Tel: +98 (21) 77536586

E-mail: hadianrs@sina.tums.ac.ir 
Nonspecific chronic LBP (CLBP) is one of the most common LBPs. It is described as persistent pain in the low back region upper to gluteal folds for at least three months without any known cause [1]. There are many conservative treatments for LBP with goals such as reduction of pain, improvement of everyday activities, and trunk range of motion (ROM) [5]. However, the most effective treatment has not been found yet [6].

Kinesio Taping (KT) is a new treatment approach that has received much attention in recent years. Kase developed KT in the 1970s [7]. KT effects include correcting muscle function by normalizing muscle tone, improving blood and lymph flow (by convolutions effects), reducing pain by neurological suppression, and improving proprioception by enhanced stimulation to cutaneous mechanoreceptors $[8,9]$. Based on these main effects, KT may improve LBP.

Few studies have ever analyzed the effect of KT on CLBP. In sum, the results of most studies indicate that KT can reduce pain and disability in subjects with LBP, but there are conflicting results for increased ROM and improvement of postural control [10-15]. A systematic review was reported that KT could improve lumbar ROM, trunk muscle endurance, and motor control in individuals with CLBP. More studies about the short-, mediate-, and long-term effects of KT on CLBP are needed to strengthen the evidence of the effectiveness of KT [16].

The purpose of the current study was to evaluate the effect of $72 \mathrm{~h}$ use of KT on low back/pelvis pain, disability, and trunk ROM in individuals with nonspecific CLBP.

\section{Materials and methods}

\section{Study design}

The study was conducted on individuals with nonspecific CLBP with single-group, pretest-posttest design. This study was in accordance with the principles of the Declaration of Helsinki, and the Ethics Committee of Tehran University of Medical Sciences approved the protocol of the study.

\section{Study Participants}

Eighteen individuals with nonspecific CLBP (9 males and 9 females), aged 25-55 years, participated in this study. All participants were referred from two public physical therapy clinics associated with Tehran Univer- sity of Medical Sciences from July 2017 to September 2018.

Individuals with LBP without radicular pain further than the buttock, lasting more than three months based on the definition of nonspecific CLBP and at least 30 of the 100-mm Numerical Rating Scale (NRS), were included in the current study.

The exclusion criteria included the history of neurological signs such as sciatica or other radicular involvement, sensory deficits, dizziness and balance impairment, spinal surgery, rheumatic diseases, diabetes, mental disorders, and pregnancy. Also, KT was immediately removed if the applied skin became itchy. All participants signed informed consent before the study.

\section{Taping technique}

We used the X application KT technique suggested by Kase et al. [7]. The base of the standard 2-in $(5 \mathrm{~cm})$ tape (Kinesio 3NS Tex Tape, made in Korea) with no tension, was attached inferior to the greater trochanter. Then, the examiner asked the participant to move into lateral flexion to the opposite side. The I shape tape was attached with moderate tension (50\%) over the tensor fascia latae and the Posterior Superior Iliac Spine (PSIS) when it reached the lateral border of erector spinae muscle. After that, the examiner asked the participant to move into lateral flexion to the same side, and the remaining tape was attached over the inferior posterior angle of the thoracic ribs with light tension. The same method was applied to the opposite side (Figure 1) [17]. In the current study, except KT, no treatments or exercises were used, and KT was applied for $72 \mathrm{~h}$.

\section{Outcomes measures}

The outcome measures were pain intensity $(1-100 \mathrm{~cm})$ on NRS, functional disability (using Oswestry Disability Index [ODI]), flexion and extension trunk ROM (using Modified-Modified Schöber Test [MMST]) and right and left lateral flexion trunk ROM (using Finger-floor Test [FFT]). All measurements were assessed at baseline (before KT) and $72 \mathrm{~h}$ after KT use in the biomechanics laboratory of Tehran University of Medical Sciences.

\section{Numerical Rating Scale}

The participants were asked to report the level of pain intensity based on NRS scores, ranging from 0 (no pain) to 100 (the worst imaginable pain) scale. The 
NRS is reliable and valid for the assessment of pain intensity $[5,8]$.

\section{Functional disability}

The Persian version of ODI was used to assess the disability of individuals with nonspecific CLBP. The questionnaire consists of 10 items related to limitations in daily tasks, and each item includes six options. The total score is calculated by adding all points and converted them into a percentage. Previous studies reported the ODI is valid and reliable for disability measurement [18].

\section{Lumbar ROM}

Lumbar flexion and extension ROM was measured by the MMST. Previous studies support the reliability and validity of the MMST for trunk ROM measurements (flexion and extension) in participants with LBP $[19,20]$. The test was done in a neutral standing position, barefoot with feet hip-distance apart. At first, the examiner drew a line connecting the two PSIS. Then marked two landmarks, one of them is the middle of the line (lower landmark), and the other is $15 \mathrm{~cm}$ above (upper landmark).

The distance between these landmarks after trunk flexion during standing was measured with a tape. The change in the difference between these landmarks was used to indicate the amount of lumbar flexion. For lumbar extension, the distance between these marks after trunk extension during standing was recorded. Then change in the difference between the landmarks was used to indicate the amount of lumbar extension.

Lumbar lateral flexion ROM on both sides was measured by the FFD test. The FFD test seems to be well accepted and commonly-used evaluation test for trunk lateral flexion ROM in a clinical setting [21, 22].

This method was performed in a neutral standing position, barefoot with feet hip-distance apart. The examiner asked the subject laterally flexed at the trunk without trunk or hip flexion or extension. The palm of his or her hand is on the flexion side with full elbow extension touched the outside of the thigh/lower leg. Then the distance between the tip of the third finger and the floor was measured. The ROM outcomes were measured bilaterally. All ROM was measured three times with a 10-minute interval; then, the average of them was analyzed.

\section{Procedure}

All outcome measures were assessed in 2 sessions, one before and then $72 \mathrm{~h}$ after KT by the same examiner. All participants completed two sessions.

\section{Statistical analysis}

The obtained data were presented as Mean $\pm \mathrm{SD}$. The data were analyzed in SPSS, v. 22. The KolmogorovSmirnov (K-S) test of normality was used for the homogeneity of the variables. Paired samples t test was used to find the differences between before and $72 \mathrm{~h}$ after KT use. The level of significance was set at $\mathrm{P}<0.05$.

\section{Results}

Eighteen patients with nonspecific CLBP ( 9 males and 9 females) with mild to moderate pain and disability and disease duration of $25.1 \pm 8.5$ months completed the study. The mean age of the subjects was $39.7 \pm 7.1$ years. Their mean BMI was $21.9 \pm 2.6 \mathrm{~kg} / \mathrm{m}^{2}$. All outcome measures were normally distributed based on the results of the K-S test $(\mathrm{P}>0.05)$. The descriptive data for all outcome measures are presented in Table 1. No adverse effects of KT were observed in our study. After $72 \mathrm{~h}$ of KT use, the NRS score significantly decreased from $48.05 \pm 17.66$ to $33.33 \pm 12.00(\mathrm{P}=0.002)$. The ODI reduced after taping, but this reduction was not statistically significant $(\mathrm{P}>0.05)$. Also, after taping, no significant differences were found for flexion, extension, and right and left lateral flexion of the lumbar area $(\mathrm{P}>0.05)$.

\section{Discussion}

The objective of the present study was to investigate the effects of KT on pain, functional disability, and trunk ROM in patients with nonspecific CLBP. Based on the obtained results after $72 \mathrm{~h}$ of taping, pain significantly decreased while the disability did not change significantly. Besides, lumbar ROM was not significantly improved.

Some studies have investigated the effects of KT on pain and functional disability in subjects with LBP [2327]. In the current study, pain significantly improved, similar to the findings of previous studies [24-28]. Although our results contradict the findings of some studies, which found significant improvements in the disability of participants after taping [23-25, 27, 28]. Our study also concurs with the results of previous studies on the effect of KT on lumbar ROM [25, 29]. 
Table 1. Mean $\pm S D$ of the analyzed variables at two time points $(n=18)$

\begin{tabular}{|c|c|c|c|}
\hline Variables & Measures & Mean $\pm S D$ & $\mathbf{P}$ \\
\hline \multirow{2}{*}{ Pain (numerical rating scale) } & Before & $48.05 \pm 17.66$ & \multirow{2}{*}{-} \\
\hline & After $72 \mathrm{~h}$ & $33.33 \pm 12.00$ & \\
\hline \multirow{2}{*}{ Disability (Oswestry Disability Index [ODI]) } & Before & $20.44 \pm 11.19$ & \multirow{2}{*}{-} \\
\hline & After $72 \mathrm{~h}$ & $17.33 \pm 6.05$ & \\
\hline \multirow{2}{*}{ Modified modified Schober test, lumbar flexion } & Before & $5.77 \pm 1.77$ & \multirow{2}{*}{-} \\
\hline & After $72 \mathrm{~h}$ & $6.27 \pm 1.75$ & \\
\hline \multirow{2}{*}{ Modified modified Schober test, lumbar extension } & Before & $3.19 \pm 1.20$ & \multirow{2}{*}{ - } \\
\hline & After $72 \mathrm{~h}$ & $3.72 \pm 1.07$ & \\
\hline \multirow{2}{*}{ Fingertip-to-floor distance test, lumbar right lateral flexion } & Before & $41.19 \pm 8.52$ & \multirow{2}{*}{-} \\
\hline & After $72 \mathrm{~h}$ & $40.30 \pm 9.60$ & \\
\hline \multirow{2}{*}{ Fingertip-to-floor distance test, lumbar Left lateral flexion } & Before & $43.36 \pm 9.43$ & \multirow[b]{2}{*}{-} \\
\hline & After $72 \mathrm{~h}$ & $40.19 \pm 11.82$ & \\
\hline
\end{tabular}

* Statistically significant at $(\mathrm{P}<0.05)$.

The general belief that KT is an effective method in decreasing pain and disability, as well as improving ROM in LBP patients, opposes the results of the current study. These findings can be explored in many aspects. According to the creators of KT, applying it on skin enhance blood and lymphatic flow that can reduce pain $[30,31]$.

There are various methods of KT application, and selecting a proper method is always essential. Only in one study, KT was applied in the lumbopelvic region, similar to the current research. They reported that using KT could improve the postural control of these patients [15].
Pain reduction after taping could probably occur by cutaneous stretch stimulation, which may interfere with the transferring and delivering afferent pain fibers, through the pain-gate control theory [31]. In addition, the potential Hawthorne effect and the placebo effect may reduce pain after KT. The finding of a systematic review showed that the impact of this intervention on spinal pain and disability is due to the placebo effect [32]. After taping, psychological factors such as improved confidence may alter pain perception $[33,34]$. All these possible explanations could be the reason for significant pain reduction versus no improvement of disability.

Figure 1. The application of Kinesio Taping

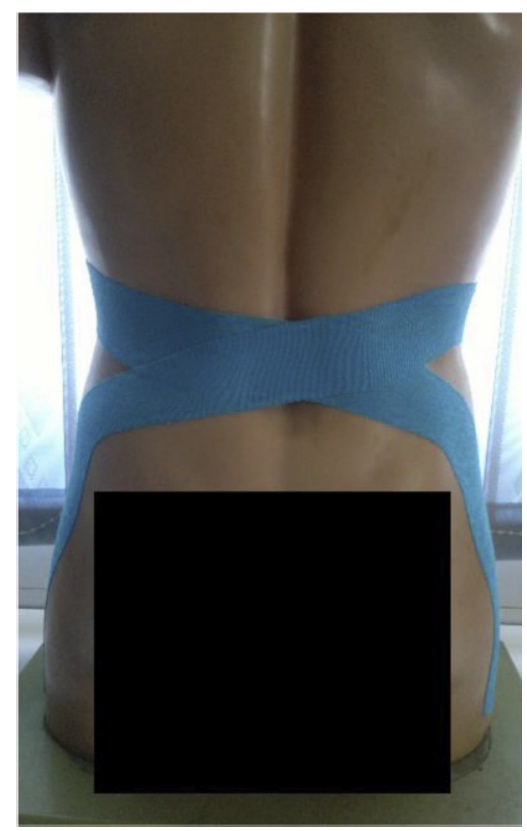


Another result of the present study showed that lumbar ROM was not significantly improved. Some of the studies suggest that KT can significantly increase the trunk ROM $[25,35,36]$. However, a literature review showed that the effect of KT on spinal motion and physiological spinal curvatures is barely noticeable [29]. In sum, the results of the studies are contradictory. Hence, it remains unknown whether the trunk ROM increases after taping within the spine area.

The taping direction may affect the ROM [29]. In the present study, the direction of taping was similar to previous studies from proximal to distal, while the influence of the reverse is unknown [29]. In the current study, X application taping with a 50\% tension was used, and the obtained results showed no improvement in trunk ROM. Trunk ROM improvement may be attributed to enhanced proprioception and following more recruitment of the motor units of the lumbar muscles $[37,38]$ It seems that the applied taping method in the current study has not been effective in improving muscle function and ROM. The final aspect refers to the duration of taping, which was $72 \mathrm{~h}$. It seems that cutaneous stretch stimulation and duration of taping have not been enough for trunk ROM improvement.

This study has some limitations, too. One limitation is the lack of a control group and a relatively small sample size. Thus, it is difficult to assess whether KT truly influences pain, disability, and lumbar ROM. Another limitation is the application of KT alone and in a short-term period. Further research is needed on the outcomes of KT applications in these patients with larger sample size and control group for longer follow-up and or with other treatments recommended by clinical practice guidelines for LBP, such as manual therapy and exercises. Therefore, KT can be a relatively effective method but may only be a short-term therapy.

\section{Conclusion}

Nonspecific CLBP is a common problem. After $72 \mathrm{~h}$ taping, the results showed that KT over the lumbopelvic region did not improve disability and lumbar ROM in people with nonspecific CLBP. However, there was a significant reduction in pain intensity. These results challenge the assumed mechanism of the KT effect. According to our results, the effect was generally insignificant, and only the improvement in pain was observed after $72 \mathrm{~h}$.

\section{Clinical implication}

The results of this study provide that KT may have some positive effect on the improvement of pain in people with nonspecific CLBP and may be used as a shortterm, symptomatic treatment in these patients.

\section{Ethical Considerations}

\section{Compliance with ethical guidelines}

This study was in accordance with the principles of the Declaration of Helsinki, and the Ethics Committee of Tehran University of Medical Sciences approved the protocol of the study.

\section{Funding}

This study was supported and approved by Tehran University of Medical Sciences

\section{Authors contributions}

Study concept and design: Soheila Abbasi and Mohammad Reza Hadian; Data Analysis: Nastaran Ghotbi and Soheila Abbasi; Interpretation of Data: Omid Rasoul and Gholam Reza Olyaei; Writing-original draft preparation: All author; Writing-review and editing: Soheila Abbasi, Omid Rasoul, and Mohammad Reza Hadian. Supervision: Mohammad Reza Hadian.

\section{Conflict of interest}

The authors declared no conflict of interest.

\section{References}

[1] Rubin DI. Epidemiology and risk factors for spine pain Neurologic Clinics. 2007; 25(2):353-71. [DOI:10.1016/j. ncl.2007.01.004] [PMID]

[2] Parthan A, Evans CJ, Le K. Chronic low back pain: Epidemiology, economic burden and patient-reported outcomes in the USA. Expert Review of Pharmacoeconomics \& Outcomes Research. 2006; 6(3):359-69. [DOI:10.1586/14737167.6.3.359] [PMID]

[3] Mohseni-Bandpei MA, Fakhri M, Ahmad-Shirvani M, Bagheri-Nessami M, Khalilian AR, Shayesteh-Azar M, et al. Low back pain in 1,100 Iranian pregnant women: Prevalence and risk factors. The Spine Journal. 2009; 9(10):795-801 [DOI:10.1016/j.spinee.2009.05.012] [PMID] 
[4] Mohseni-Bandpei MA, Fakhri M, Ahmad-Shirvani M, Bagheri-Nessami M, Khalilian AR. [Epidemiological aspects of low back pain in nurses (Persian)]. Journal of Babol University of Medical Sciences. 2005; 7(2):35-40. https://www.sid.ir/fa/ journal/ViewPaper.aspx?ID=17342

[5] Jensen MP, Turner JA, Romano JM, Fisher LD. Comparative reliability and validity of chronic pain intensity measures. Pain. 1999; 83(2):157-62. [DOI:10.1016/S0304-3959(99)001013]

[6] van Tulder MW, Koes BW, Bouter LM. Conservative treatment of acute and chronic nonspecific low back pain: A systematic review of randomized controlled trials of the most common interventions. Spine. 1997; 22(18):2128-56. [DOI:10.1097/00007632-199709150-00012] [PMID]

[7] Kase K, Wallis J, Kase T. Clinical therapeutic applications of the Kinesio Taping methods. Tokyo: Kinesio Taping Assoc.; 2003. https://books.google.com/ books?id=uix5PgAACAAJ\&dq

[8] Kase K, TH, Tomoki O. Development of kinesio tape, kinesio taping perfect manual. kinesio taping association. 1996;610:117-8

[9] Murray H, Husk L. Effect of kinesio taping on proprioception in the ankle. J Orthop Sports Phys Ther. 2001; 31(1). https://www.ncbi.nlm.nih.gov/pmc/articles/PMC3896108/

[10] Kaplan Ş, Alpayci M, Karaman E, Çetin O, Özkan Y, İlter $\mathrm{S}$, et al. Short-term effects of Kinesio Taping in women with pregnancy-related low back pain: A randomized controlled clinical trial. Medical Science Monitor. 2016; 22:1297-301. [DOI:10.12659/MSM.898353] [PMID] [PMCID]

[11] Sathya P, Ramakrishnan KS, Phadke SSD, Jena R. Comparison of Kinesio Taping with mckenzie and only mckenzie technique in the treatment of mechanical low back pain. International Journal of

[12] Therapies and Rehabilitation Research. 2016; 5(4):28-32. [DOI:10.5455/ijtrr.000000140]

[13] Kelle B, Güzel R, Sakallı H. The effect of Kinesio taping application for acute non-specific low back pain: A randomized controlled clinical trial. Clinical Rehabilitation. 2016; 30(10):997-1003. [DOI:10.1177/0269215515603218] [PMID]

[14] Grześkowiak M, Szulc P, Szwedziak M, Lewandowski J. [The effect of the Kinesio Taping method on spinal motion and physiological spinal curvatures. Literature review (Polish)]. Ortopedia Traumatologia Rehabilitacja. 2014; 16(2):2216. https://ortopedia.com.pl/resources/html/article/ details?id=22784

[15] Preece H, White P. Does kinesiology tape increase trunk forward flexion? Journal of Bodywork and Movement Therapies. 2017; 21(3):618-25. [DOI:10.1016/j.jbmt.2016.09.011] [PMID]

[16] Abbasi S, Rojhani-Shirazi Z, Shokri E, San José FGM. The effect of Kinesio Taping on postural control in subjects with non-specific chronic low back pain. Journal of Bodywork and Movement Therapies. 2018; 22(2):487-92. [DOI:10.1016/j. jbmt.2017.06.003] [PMID]

[17] Nelson NL. Kinesio Taping for chronic low back pain: A systematic review. Journal of Bodywork and Movement Therapies. 2016; 20(3):672-81. [DOI:10.1016/j.jbmt.2016.04.018] [PMID]
[18] Farrar JT, Young Jr JP, LaMoreaux L, Werth JL, Michae Poole R. Clinical importance of changes in chronic pain intensity measured on an 11-point numerical pain rating scale. Pain. 2001; 94(2):149-58. [DOI:10.1016/S0304-3959(01)003499]

[19] Mousavi SJ, Parnianpour M, Mehdian H, Montazeri A Mobini B. The Oswestry disability index, the Roland-Morris disability questionnaire, and the Quebec back pain disability scale: Translation and validation studies of the Iranian versions. Spine. 2006; 31(14):E454-E9. [DOI:10.1097/01 brs.0000222141.61424.f7] [PMID]

[20] Tousignant M, Poulin L, Marchand S, Viau A, Place C. The modified-modified schober test for range of motion assessment of lumbar flexion in patients with low back pain: A study of criterion validity, intra-and inter-rater reliability and minimum metrically detectable change. Disability and Rehabilitation. 2005; 27(10):553-9. [DOI:10.1080/09638280400018411] [PMID]

[21] Williams R, Binkley J, Bloch R, Goldsmith CH, Minuk T. Reliability of the modified-modified Schöber and double inclinometer methods for measuring lumbar flexion and extension. Physical Therapy. 1993; 73(1):26-37. [DOI:10.1093/ $\mathrm{ptj} / 73.1 .26]$

[22] Jonsson E, Ljungkvist I, Hamberg J. Standardized measurement of lateral spinal flexion and its use in evaluation of the effect of treatment of chronic low back pain. Upsala Journal of Medical Sciences. 1990; 95(1):75-86. [DOI:10.3109/03009739009178578] [PMID]

[23] Hecimovich MD, Hebert JJ. Reliability and concurrent validity of an alternative method of lateral lumbar range of motion in athletes. South African Journal of Sports Medicine 2016; 28(1):23-6. [DOI:10.17159/2078-516X/2016/v28i1a1414]

[24] Kim CH, Kim AR, Kim MI, Kim SH, Yoo HJ, Lee SH The efficacy of Kinesio Taping in patients with a low back pain. Journal of the Korean Academy of Family Medicine. 2002; 23(2):197-204. https://www.kjfm.or.kr/journal/view. php?number $=834$

[25] AlBahel F, Hafez AR, Zakaria AR, Al-Ahaideb A, Buragadda S, Melam GR. Kinesio Taping for the treatment of mechanical low back pain. World Applied Sciences Journal. 2013; 22(1):78-84. https://pdfs.semanticscholar.org/562c/ d91d6705c1f3fcd4496dc6023563d24a0826.pdf

[26] Castro-Sánchez AM, Lara-Palomo IC, Matarán-Peñarrocha GA, Fernández-Sánchez M, Sánchez-Labraca N, Arroyo-Morales $\mathrm{M}$. Kinesio Taping reduces disability and pain slightly in chronic non-specific low back pain: A randomised trial. Journal of Physiotherapy. 2012; 58(2):89-95. [DOI:10.1016/ S1836-9553(12)70088-7]

[27] Park KS, Ryoo EN, Choi MH. The effect of balance taping therapy on pain of the lower back pain patient. Journal of Korean Academy of Adult Nursing. 2005; 17(1):77-87. https:/ / www.koreamed.org/article/0094JKAAN/2005.17.1.77

[28] Sathya P, Ramakrishnan K, Shweta S, Wahyono A, Lee $\mathrm{SB}$, Yeo SH, et al. Comparision of Kinesio Taping with mckenzie and only mckenzie technique in the treatment of mechanical low back pain. International Journal of Therapies and Rehabilitation Research. 2016; 5(4):28-32. [DOI:10.5455/ ijtrr.000000140] 
[29] Salvat Salvat I, Alonso Salvat A. [Immediate effects of Kinesio Taping on trunk flexion (Spanish)]. Fisioterapia. 2010; 32(2):57-65. [DOI:10.1016/j.ft.2009.10.005]

[30] Grześkowiak M, Szulc P, Szwedziak M, Lewandowski J. The effect of Kinesiology Taping on spinal motion and physiological spinal curvatures. A literature review. Trends in Sport Sciences. 2014; 21(1):33-7. https://www.wbc.poznan. pl/Content/325869/PDF/7_Trends_Vol21_2014_\%20 no1_34.pdf

[31] Kase K, Wallis J, Kase T. Clinical therapeutic applications of the Kinesio Taping method. Albuquerque. 2003.

[32] Kneeshaw D. Shoulder taping in the clinical setting. Journal of Bodywork and Movement Therapies. 2002; 6(1):2-8. [DOI:10.1054/jbmt.2001.0233]

[33] Vanti C, Bertozzi L, Gardenghi I, Turoni F, Guccione AA, Pillastrini P. Effect of taping on spinal pain and disability: Systematic review and meta-analysis of randomized trials. Physical Therapy. 2015; 95(4):493-506. [DOI:10.2522/ptj.20130619] [PMID]

[34] GonzáLez-Iglesias J, Fernández-de-las-Peñas C, Cleland J Huijbregts P, Gutiérrez-Vega MDR. Short-term effects of cervical Kinesio Taping on pain and cervical range of motion in patients with acute whiplash injury: A randomized clinical trial. Journal of Orthopaedic \& Sports Physical Therapy. 2009; 39(7):515-21. [DOI:10.2519/jospt.2009.3072] [PMID]

[35] Saavedra-Hernández M, Castro-Sánchez AM, Arroyo-Morales M, Cleland JA, Lara-Palomo IC, Fernández-de-las-Peñas C. Short-term effects of Kinesio Taping versus cervical thrust manipulation in patients with mechanical neck pain: A randomized clinical trial. Journal of Orthopaedic \& Sports Physical Therapy. 2012; 42(8):724-30. [DOI:10.2519/jospt.2012.4086] [PMID]

[36] Lemos TV, Albino ACG, Matheus JPC, de Melo Barbosa A. The effect of Kinesio Taping in forward bending of the lumbar spine. Journal of Physical Therapy Science. 2014; 26(9):1371-5. [DOI:10.1589/jpts.26.1371] [PMID] [PMCID]

[37] Grigg P. Peripheral neural mechanisms in proprioception Journal of Sport Rehabilitation. 1994; 3(1):2-17. [DOI:10.1123/ jsr.3.1.2]

[38] Riemann BL, Lephart SM. The sensorimotor system, part II: The role of proprioception in motor control and functional joint stability. Journal of Athletic Training. 2002; 37(1):80-4. [PMID] [PMCID] 
This Page Intentionally Left Blank 